\section{Electronically Controlled Root Heating Tubes}

\author{
Dewayne L. Ingram ${ }^{1}$, Brett H. Basford ${ }^{2}$, William J. Foster ${ }^{3}$, and \\ Christopher Ramcharan ${ }^{3}$ \\ Department of Environmental Horticulture, IFAS, University of Florida, \\ Gainesville, FL 32611
}

Additional index words. root-zone temperatures, container medium

\begin{abstract}
A solid-state, electronic controller was designed and built to maintain de"sired root-zone temperatures in specially designed root heating tubes. The controller uses a thermistor feedback mechanism to an operational amplifier circuit. The tubes were constructed from $7.5-\mathrm{cm}$-diameter metal pipe, electrical heating tape, a rubber coating, and pipe insulation. Each controller can maintain treatment temperatures in 16 tubes; four tubes at each of four temperatures. Temperatures can be maintained from ambient to $50 \mathrm{C}$ with a precision at 35 of $\pm 0.9 \mathrm{C}$ within and between tubes.
\end{abstract}

Precise control of temperatures in growth media can be a limiting factor in determining plant response to specific root-zone temperatures. Systems to maintain precise root-zone temperatures are usually expensive and cumbersome, with little flexibility to" accommodate changing experimental designs. Facilities where plant root systems in waterproof containers have been suspended in temperaturecontrolled water baths (Gur et al., 1972 Wong et al., 1971) and air-bath boxes with heat provided from shielded light bulbs (Johnson and Ingram, 1984; Pellett et al., 1973) have been used to provide root-zone temperature treatments. Improper aeration of the growth medium, considerable temperature gradation in the medium from side to side and top to bottom, and their inflexible nature are among the disadvantages of these systems. Graves and Dana (1987) presented a system that circulates water from a reservoir to individual units in which plants in water-tight containers are inserted. This system allows for a wide range of root-zone temperatures and independent experimental units but offers the disadvantage of maintaining a relatively large water reservoir for each temperature treatment.

In an attempt to design a flexible system that would maximize precision and minimize temperature gradients, several prototype systems were tested. Forced air to individual containers provided uniform temperatures in the growth medium, but the low relative humidity of the air moving slowly through the medium dried the roots excessively. The system was also somewhat inflexible. Circulating a fluid around individual containers provided acceptable temperature control, but

Received for publication 27 June 1989. Florida Experiment Station Journal Series no. 10058. We gratefully acknowledge the assistance of Claudia Larsen. The cost of publishing this paper was defrayed in part by the payment of page charges. Under postal regulations, this paper therefore must be hereby marked advertisement solely to indicate this fact.

'Professor.

${ }^{2}$ Previous Student Assistant.

${ }^{3}$ Former Graduate Research Assistant. nized metal stove pipe, $3 \mathrm{~m}$ of $60-\mathrm{W} 120$ - the volume of fluid required and the need for a heating system for each treatment temperature were disadvantages. The system design reported here consisted of electrical heating of cylindrical tubes that were controlled by solid-state electronic controllers.

Each root heating tube was constructed of $7.5 \times 23-\mathrm{cm}$ (diameter $\times$ length) galvaVAC heating tape, and 1.25 -cm-thick foam insulation (Fig. 1). A polyethylene bag 7.5 $\times 26 \mathrm{~cm}$ (diameter $\times$ height), with six holes punched in the bottom for drainage, was filled with growth medium for the test plant and inserted into the root heating tube. The root heating tube controller can maintain four independent temperatures simultaneously with up to four tubes at each temperature. The controller circuitry was based on thermistor feedback to an operational amplifier circuit (Fig. 2). This principle involves the manual adjustment of a variable resistor for a desired temperature. This established resistance is compared to the resistance of a thermistor

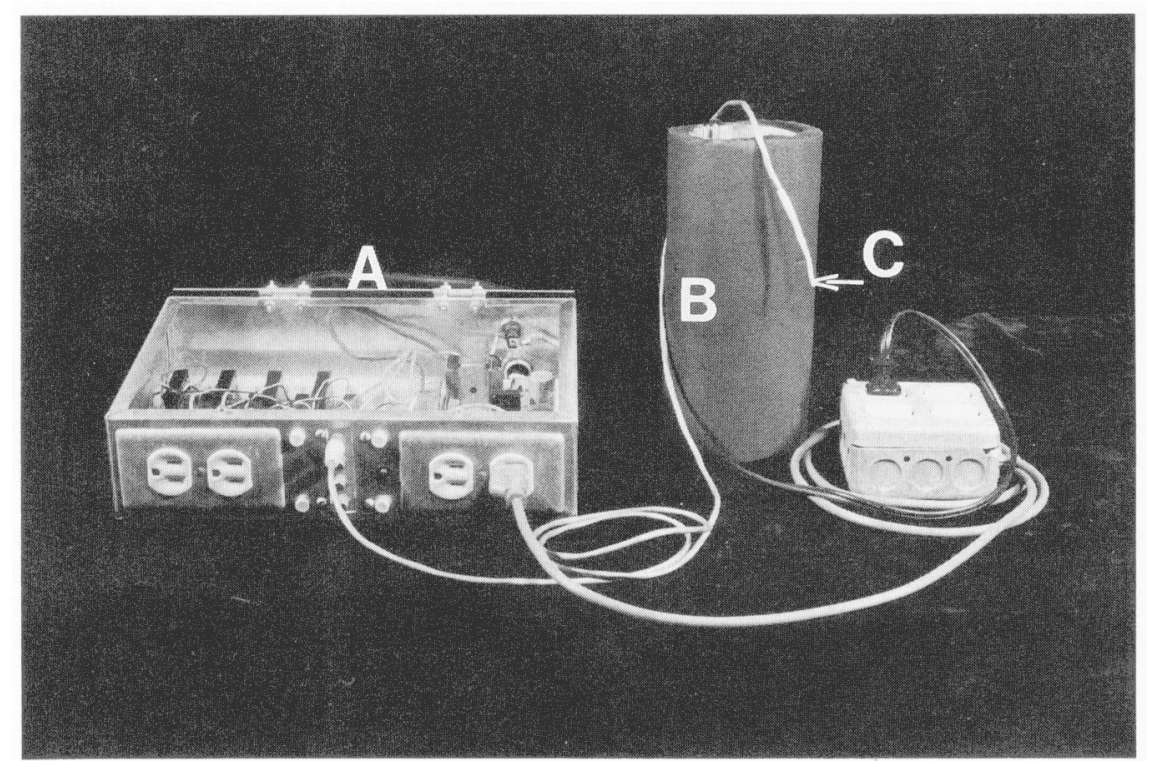

Fig. 1. Electronic controller (A) with one of a possible 16 root heating tubes (B) connected. The thermistor $(\mathrm{C})$ is inserted between the polyethylene bag container and the inside sidewall of the root heating tube. positioned on the inside wall of a root heating tube controlled by that channel. The operational amplifier circuit turns off the electrical current to the tube when zero potential across its inputs is realized. This comparison of resistance and the turn-on/turn-off cycle continues instantaneously and indefinitely until the controller is disconnected. A detailed description of the construction, testing, installation, and operation of this system is available from the authors. The approximate material cost for one controller, 16 root heating tubes, and necessary hardware is $\$ 350$. Electrical engineering students were hired to construct the controllers.

The system has been evaluated over the temperature range of 30 to $45 \mathrm{C}$. The precision of temperature control does not differ over this temperature range; therefore, the analysis of an on/off cycle-for a root-zone temperature of $35 \mathrm{C}$ is presented here. A controller and eight tubes containing growth medium in a polyethylene bag were placed in a walk-in growth room with 1100 $\mu \mathrm{mol} \cdot \mathrm{s}^{-1} \cdot \mathrm{m}^{-2}$ irradiance provided with 1000 W phosphor-coated metal-arc HID lamps (GTE Sylvania, Manchester, N.H.). The growth medium consisted of Metro 500 (W.R. Grace, Cambridge, Mass.) and was irrigated to container capacity $12 \mathrm{hr}$ before the tests were initiated. Welded copper-constantan thermocouples were placed in four locations in the growth medium of eight tubes. The locations were: Top- $1.2 \mathrm{~cm}$ from the top surface of the medium and $1 \mathrm{~cm}$ from the polyethylene bag; middle side-at the interface between the medium and the polyethylene bag, half-way between the top and bottom; middle center-the center of the growth medium; and bottom-1.2 $\mathrm{cm}$ from the bottom surface and $1 \mathrm{~cm}$ from the polyethylene bag located on the opposite side from the top thermocouple. Two controller channels were adjusted to maintain 35C for $6 \mathrm{hr}$ in the corresponding eight tubes. Aluminum 


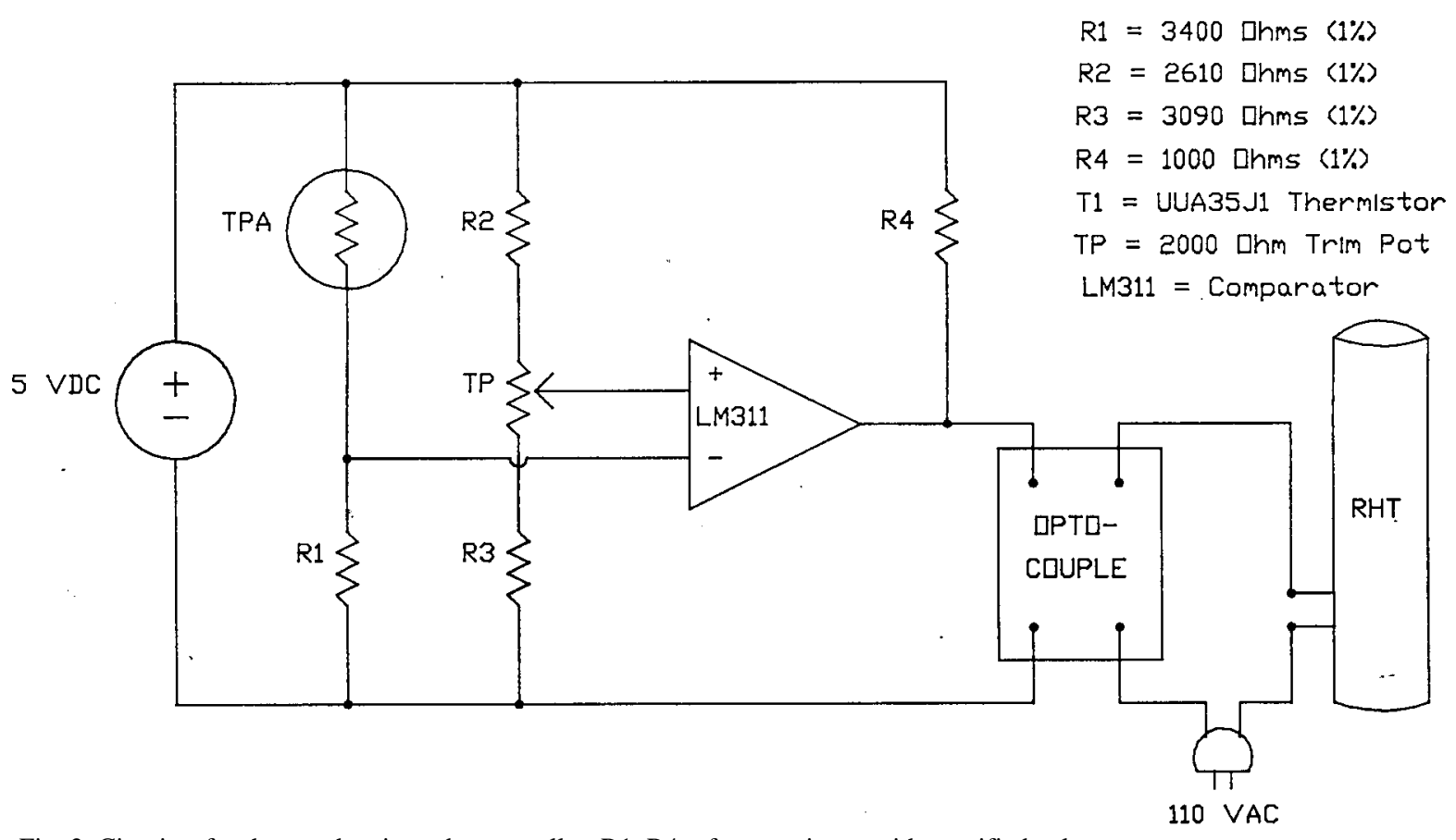

Fig. 2. Circuitry for the root heating tube controller. R1-R4 refer to resistors with specified values.

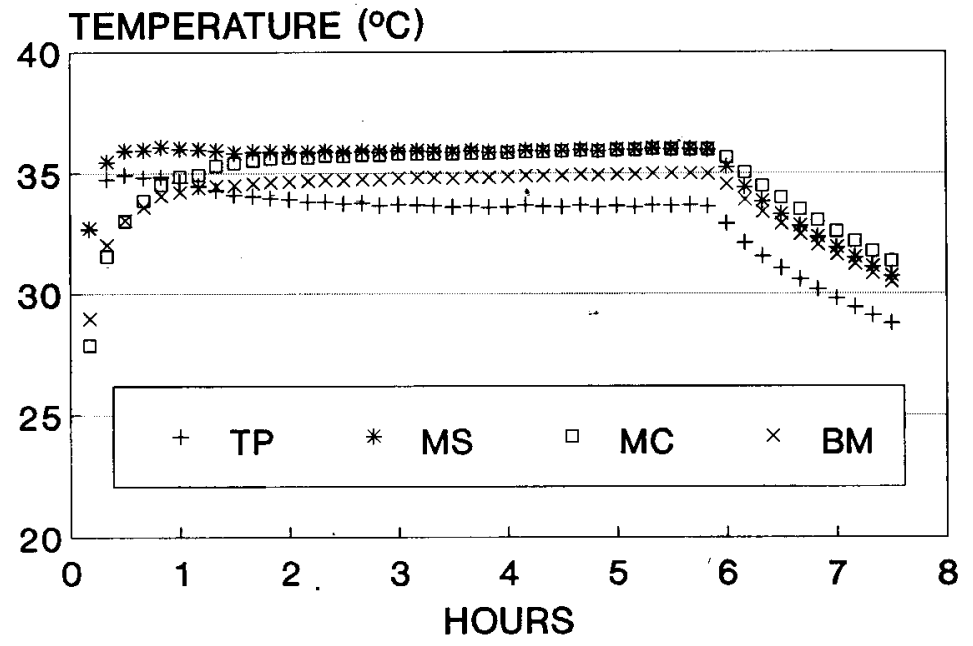

Fig. 3. Temperature fluctuations at four positions in root heating tubes. $\mathrm{TP}=$ top, $\mathrm{MS}=$ middleside, $\mathrm{MC}=$ middle-center, and $\mathrm{BM}=$ bottom. Individual points are means of eight replicates.

foil shields were placed on the top of each heating tube to minimize direct radiation interception on the noninsulated top surface. Temperatures were recorded every $10 \mathrm{~min}$ for $8 \mathrm{hr}$ with a Campbell 21X Datalogger (Campbell Scientific, Logan, Utah) with welded copper-constantan thermocouples. Means and SE for the eight replicate tubes were calculated.

The desired 35C was achieved at the top, middle side, and middle center positions within $30 \mathrm{~min}$ (Fig. 3). The temperature in the bottom position reached its maximum within $1 \mathrm{hr}$ and remained $\approx 1$ degree centigrade below that at the top and middle positions. This was probably due to the higher growth medium moisture content at the bot- tom of the polyethylene bag. The moisture contents at the initiation-of the treatments averaged $40 \%, 43 \%$, and $56 \%$ by volume at the top, middle, and bottom positions, respectively. The greater specific heat of the medium at higher water content may account for the reduced rate of temperature increase at the bottom position compared to the positions at the middle and top. The bottom of the heating tube was not insulated for fear of disrupting drainage. Alternative means of insulating while ensuring drainage need to be explored.

The average temperatures maintained between hours 1 and 6 at the top, middle-center, middle-side, and bottom positions were $34.2 \pm 0.4,35.9 \pm 0.4,35.3 \pm 0.7$, and
$34.4 \pm 0.7 \mathrm{C}$, respectively. The mean temperature across all four positions, eight heating tubes, and hours 1 through 6 was 35.0 $\pm 0.9 \mathrm{C}$.

Abetter understanding of plant response to supraoptimal root-zone temperatures can be achieved when the temperature treatments imposed are precisely defined and controlled. The precision, flexibility, and cost of this root heating tube system make it attractive for providing root-zone temperature treatments. The primary disadvantage of this system is that the minimum root-zone temperature treatment is limited by the ambient air temperature. The system should be monitored daily and component functions should be evaluated between experiments. Thermistors should be replaced in 1 or 2 years. Our system has been operating with few problems for 5 years.

\section{Literature Cited}

Graves, W.R. and M.N. Dana. 1987. A system to control root-zone temperature. HortScience 22:957-958.

Gur, A., B. Braudo, and Y. Mizrahi. 1972. Physiological responses of apple trees to supraoptimal root temperature. Physiol. Plant. 27:130138.

Johnson, C.R. and D.L. Ingram. 1984. Pittosporum tobira response to container medium temperature. HortScience 19:524-525.

Pellett, H., C. Anderson, and C. Allen. 1973. A simplified soil temperature regulation system. HortScience 4:64-65.

Wong, T. L., R.W. Harris, and R.E. Fissell. 1971 Influence of high soil temperatures on five woody plant species. J. Amer. Soc. Hort. Sci. 96:8082. 